\title{
Comparison of conventional polymerase chain reaction and routine blood smear for the detection of Babesia canis, Hepatozoon canis, Ehrlichia canis, and Anaplasma platys in Buriram Province, Thailand
}

\author{
Rucksak Rucksaken ${ }^{1}$, Cherdsak Maneeruttanarungroj ${ }^{2,3}$, Thanaporn Maswanna ${ }^{4}$, Metita Sussadee ${ }^{1}$ and Pithai Kanbutra ${ }^{5}$
}

1. Department of Veterinary Technology, Faculty of Veterinary Technology, Kasetsart University, Bangkok, Thailand; 2. Department of Biology, Faculty of Science, King Mongkut's Institute of Technology Ladkrabang, Bangkok, Thailand;

3. Bioenergy Research Unit, Faculty of Science, King Mongkut's Institute of Technology Ladkrabang, Bangkok, Thailand;

4. Scientific Instrument Center, Faculty of Science, King Mongkut's Institute of Technology Ladkrabang, Bangkok,

Thailand; 5. Veterinary Teaching Hospital, Faculty of Veterinary Medicine, Khon Kaen University, Khon Kaen, Thailand. Corresponding author: Rucksak Rucksaken, e-mail: cvtrsr@ku.ac.th

Co-authors: CM: cherdsak.ma@kmitl.ac.th, TM: bow_508ii@hotmail.com, MS: cvtmts@ku.ac.th, PK: kpitha@kku.ac.th Received: 11-12-2018, Accepted: 02-04-2019, Published online: 24-05-2019

doi: 10.14202/vetworld.2019.700-705 How to cite this article: Rucksaken R, Maneeruttanarungroj C, Maswanna T, Sussadee M, Kanbutra P (2019) Comparison of conventional polymerase chain reaction and routine blood smear for the detection of Babesia canis, Hepatozoon canis, Ehrlichia canis, and Anaplasma platys in Buriram Province, Thailand, Veterinary World, 12(5): 700-705.

\begin{abstract}
Background and Aim: Dog blood parasites are important tick-borne diseases causing morbidity and mortality in dogs worldwide. Four dog blood parasites species are commonly found in Thailand: Babesia canis, Hepatozoon canis, Ehrlichia canis, and Anaplasma platys. They are transmitted easily by tick species. However, there is little prevalence data available in Thailand. Diseases presentation of blood parasites infection is similar, but the treatment of each species is different. Current diagnosis mainly relies on microscopic examination of a stained blood smear, which has low sensitivity. Therefore, accurate diagnosis is important. This study aims to evaluate the efficacy of the conventional polymerase chain reaction (PCR) method and routine blood smears in the detection of four blood parasites species in dogs from Buriram Province, Thailand.

Materials and Methods: In total, 49 EDTA-blood samples were collected from dogs in Buriram Province, Thailand. Blood parasite infection was compared using the Giemsa-stained blood smear technique to identify the parasite under a $100 \times$ oil immersion with PCR amplification of the $18 \mathrm{~S}$ rDNA gene of B. canis and $H$. canis and the $16 \mathrm{~S}$ rDNA gene of E. canis and A. platys.

Results: Only one dog out of 49 was positive for $H$. canis based on microscopic examination whereas the PCR results showed that 2.04\% (1/49), 4.08\% (2/49), 36.73\% (18/49), and 30.61\% (15/49) of dogs were positive for B. canis, H. canis, E. canis, and A. platys, respectively. Moreover, coinfection was found in $16.33 \%(8 / 49)$ of dogs.

Conclusion: This study is the first report to demonstrate the molecular prevalence of blood parasites in domestic dogs in Buriram Province. The results indicated that the PCR method exhibited much higher sensitivity and reliability for blood parasites diagnosis in dogs. Therefore, our data support serious concern regarding the diagnostic technique used in routine blood testing and also provide prevalence data for the management and control of blood parasites in this area.
\end{abstract}

Keywords: Blood parasites, dog, polymerase chain reaction, prevalence.

\section{Introduction}

Blood parasites infection is an important health problem causing morbidity and mortality in dogs worldwide [1-7]. In Thailand, dog blood parasites have spread throughout the country, with the four known types of vector-borne parasites being Babesia spp., Hepatozoon canis, Ehrlichia canis, and Anaplasma platys [3,8-11]. Babesia canis and H. canis are intracellular protozoa belonging to the phylum Apicomplexa while $E$. canis and $A$. platys are Gram-negative, obligate intracellular organisms belonging to the Order Rickettsiales. These four parasites share the common

Copyright: Rucksaken, et al. Open Access. This article is distributed under the terms of the Creative Commons Attribution 4.0 International License (http://creativecommons.org/licenses/ by/4.0/), which permits unrestricted use, distribution, and reproduction in any medium, provided you give appropriate credit to the original author(s) and the source, provide a link to the Creative Commons license, and indicate if changes were made. The Creative Commons Public Domain Dedication waiver (http:// creativecommons.org/publicdomain/zero/1.0/) applies to the data made available in this article, unless otherwise stated. vector, the brown dog tick (Rhipicephalus sanguineus) which is the most common tick species found in dogs in Thailand [12]. Dogs generally get infected through infected tick bites in the case of B. canis, E. canis, and A. platys or through ingestion of the infected tick in the case of $H$. canis. Blood parasites are also transmitted to another dog by blood transfusion $[13,14]$. From previous studies in Thailand, the prevalence of Babesia spp. infections were $6.3 \%, 9.4 \%$, and $19.5 \%$ in Maha Sarakham, Songkhla, and Khon Kaen Provinces, respectively $[3,8,9]$. The prevalence of Hepatozoon spp. infections were $10.1 \%, 18.8 \%$, and $11.4 \%$ in Maha Sarakham, Songkhla, and Bangkok Provinces, respectively $[3,8,11]$. The prevalence of $E$. canis was $21.5 \%, 3.9 \%$, and $1.3 \%$ in Maha Sarakham, Songkhla, and Khon Kaen Provinces, respectively [3,8,9], and A. platys infection has been reported only in Songkhla Province with $4.4 \%$ prevalence [8]. Moreover, coinfection between $B$. canis and E. canis has been reported in $2.5 \%$ of dogs in Maha Sarakham Province [3]. 
Dog blood parasites cause similar disease presentations ranging from subclinical to severe pathology involving blood cells and multiple organs [1,2,4,15-18]. Common symptoms include fever, hemolytic anemia, thrombocytopenia, splenomegaly, and organ dysfunction $[18,19]$. Coinfection with other blood parasites has clinical importance because it complicates diagnoses, exacerbates clinical signs, reduces the effectiveness of treatment, and can worsen the prognosis $[20,21]$. Nowadays, the diagnosis of dog blood parasites in Thailand is mainly based on microscopic examination of blood smears. However, this technique has low sensitivity, particularly in low parasitemia cases, and it also requires an experienced examiner [22-24]. A serological diagnostic kit has been used for diagnosis of Ehrlichia spp. and Anaplasma spp. in Thailand, but the major limitation of a serological test is that it cannot discriminate between recent and present infection [25]. Polymerase chain reaction (PCR) is a widely used molecular technique to confirm blood parasite infection because it has high sensitivity and specificity $[3,9,10,26,27]$.

In Thailand, little epidemiological data are available, and no comparison between PCR detection and blood smear has been reported. Therefore, we aimed to identify the efficacy of the conventional PCR compared with blood smear technique to survey the prevalence of B. canis, H. canis, E. canis, and A. platys in domestic dogs from Prakhon Chai district, Buriram Province, Thailand.

\section{Materials and Methods}

\section{Ethical approval}

This study was approved by the Animal Ethics Committee of the Faculty of Veterinary Technology, Kasetsart University, Thailand (ACKU61-VTN-004).

\section{Dog blood sample collection}

Forty-nine ethylenediaminetetraacetic acid (EDTA) blood samples were randomly collected from domestic dogs in Prakhon Chai district, Buriram Province, Thailand. $21(42.86 \%)$ were males and 28 $(57.14 \%)$ were females. All dog had no obvious clinical signs of blood parasite infections at the time of blood collection such as fever, lethargy, emaciation, or pale mucous membrane. EDTA blood samples were stored at $-20^{\circ} \mathrm{C}$ until extraction of DNA. The positive samples for B. canis, H. canis, E. canis, and A. platys infection confirmed by blood smear were used as positive controls. All positive controls were obtained from the Veterinary Teaching Hospital, Faculty of Veterinary Medicine, Khon Kaen University, Thailand.

\section{Blood smears}

Blood smears were performed on the same day as blood collection. After being air-dried, the thin smears were fixed in methanol and were stained for $20 \mathrm{~min}$ in Giemsa stain. The slides were then rinsed with tap water, air-dried, and examined using a 100× oil immersion objective lens. Areas that were wellstained, free of stain precipitate, and well-populated were selected and examined on at least 100 fields of view.

\section{DNA extraction}

DNA was extracted from $200 \mu 1$ of whole blood using FavorPrep Blood Genomic DNA Extraction Mini Kit (Favorgen Biotech Corp.) according to the manufacturer's protocol. Briefly, $20 \mu 1$ proteinase $\mathrm{K}$ and $200 \mu 1 \mathrm{FABG}$ buffer were added to the samples, which were then mixed and incubated at $60^{\circ} \mathrm{C}$ for $15 \mathrm{~min}$ to lyse the cells. The tube was centrifuged to remove drops on the cap and then $200 \mu \mathrm{l}$ absolute ethanol was added to the sample. After mixing thoroughly using pulse-vortexing for $10 \mathrm{~s}$ and briefly spinning the tube to remove drops, the mixture was placed in a FABG Mini Column, washed, and eluted for DNA solution.

\section{Primer design and PCR amplification}

All primers were designed using the Primer3 program online tool available at http://bioinfo.ut.ee/ primer3-0.4.0/to flank around the selected DNA region. For the $18 \mathrm{~S}$ rDNA gene, three DNA sequences of B. canis vogeli (Acc. No. AY072925.1), B. canis canis (Acc. No. AY072926.1), and H. canis (Acc. No. DQ439543.1) were retrieved from the NCBI nucleotide database and used as input for DNA alignment with Clustal Omega which was available online at https:// www.ebi.ac.uk/Tools/msa/clustalo/. The polymorphic regions were used to target DNA priming. For the $16 \mathrm{~S}$ rDNA gene, two sequences, E. canis (EU178797.1) and $A$. platys (LC269820.1), were downloaded from the same database and the same strategy was adopted as used in the $18 \mathrm{~S}$ rDNA design. All designed primers used in the experiment are listed in Table-1.

PCR was performed using the newly designed primers for amplification of the 18S rDNA sequences of $B$. canis and $H$. canis and the 16S rDNA sequences of $E$. canis and A. platys. Positive samples of B. canis, $H$. canis, E. canis, and A. platys were used as positive

Table-1: Targeted genes and list of new primers used in this study.

\begin{tabular}{lcll}
\hline Gene & Primer name & Sequence $\left.\mathbf{( 5 '}^{\prime} \mathbf{3} \mathbf{3}^{\prime}\right)$ & Product size \\
\hline 18S rDNA & BH18SF & AATTGGAGGCAAGTCTGGT & 356 bp (for Babesia canis vogeli) \\
& BH18SR & TGCTTTCGCAGTAGTTYGTC & 357 bp (for Babesia canis canis) \\
& & 409 bp (for Hepatozoon canis) \\
16S rDNA & 16SFEhr & CTGCTAGACTAGAGGTCGAA & 181 bp (for Ehrlichia canis) \\
& 16SFAna & GGGCATGTAGGCGGTTCG & 250 bp (for Anaplasma platys) \\
\hline
\end{tabular}


controls. The PCR reactions were performed in a 50 $\mu 1$ reaction composed of $1 \times$ DreamTaq Green buffer (Thermo Scientific), $0.2 \mathrm{mM}$ dNTP each, $1 \mu \mathrm{M}$ of each DNA primer, $100 \mathrm{ng}$ of DNA template, 1.25 units of DreamTaq DNA polymerase (Thermo Scientific), and ultrapure sterile water up to $50 \mu 1$. The amplification procedure consisted of the following steps: 2 min at $95^{\circ} \mathrm{C}$ for initial denaturation, denaturation for $30 \mathrm{~s}$ at $95^{\circ} \mathrm{C}$, annealing for $30 \mathrm{~s}$ at $55^{\circ} \mathrm{C}$, and extension for $30 \mathrm{~s}$ at $72^{\circ} \mathrm{C}$. Steps $2-4$ were repeated for another 39 cycles and followed by a final extension for $5 \mathrm{~min}$ at $72^{\circ} \mathrm{C}$. The PCR products were identified using $1.0 \%$ agarose gel electrophoresis stained with SYBR Safe DNA gel stain (Thermo Scientific) to verify the amplicon size under UV light. 19 PCR products were randomly selected from the positive PCR products and subjected to nucleotide sequencing. All DNA sequences were later aligned to either $18 \mathrm{~S}$ rDNA or $16 \mathrm{~S}$ rDNA templates to confirm the identity of the amplified fragment.

\section{Statistical analysis}

SPSS version 25.0 was used for statistical analysis. Agreement between the blood smear and PCR techniques was determined using the Kappa $(\mathrm{K})$ test.

\section{Results}

\section{Primer design}

Both 18S rDNA and 16S rDNA genes serve as a housekeeping gene and have a high copy number in their genomes of eukaryotes and prokaryotes, respectively, allowing us to have sufficient amount of DNA template for PCR amplification in light infection. The DNA alignment of those genes using Clustal Omega revealed the polymorphic regions among the same genes. These regions showed promising capacity in the primer design for use as a molecular marker separating the species-specific infection. For the $18 \mathrm{~S}$ primer, the forward and reverse primers were designed at the same position flanking the insertion region of $H$. canis and making the amplicon size larger than the fragment from $B$. canis. It should be noted that the DNA alignment between $B$. canis canis and B. canis vogeli revealed a slightly different DNA sequence with a 1-bp missing base in $B$. canis vogeli (shaded area in Figure-1a) making subspecies identification possible using some molecular detection techniques such as DNA sequencing or single-strand conformation polymorphism.

In the $16 \mathrm{~S}$ rDNA primer design, the forward primers were designed to contain a species-specific selection using the 3' end priming site. Since only the 3 'end priming of the primer would play an important role in the DNA extension process, the 16SFAna primer was designed to have a 4-bp specific binding site at the 3' end of the A. platys template, whereas the 16SFEhr primer contained a 2-bp specific binding site at the 3' end of the E. canis template (Figure- $1 \mathrm{~b}$ ). These specificities would allow the successful amplification by certain parasite templates. A reverse primer was used for both species priming.

\section{Blood smear and PCR prevalence rates}

Out of the 49 dogs, only $2.04 \%$ ( $1 \mathrm{dog}$ ) was observed as positive for $H$. canis infection, which was identified using Giemsa-stained blood smear examination under a light microscope. On the other hand, the PCR results showed that $57.14 \%$ (28/49) of dogs were positive for at least one blood parasite infection and the greatest prevalence was with $E$. canis corresponding to $36.73 \%$ (18/49) with lower values for A. platys, $H$. canis, and B. canis infection with the prevalence scores of $30.61 \%(15 / 49), 4.08 \%(2 / 49)$, and $2.04 \%(1 / 49)$ of dogs, respectively. Examples of successfully amplified DNA bands are shown in Figure-2a-d, respectively, at 356 bp for B. canis, 409

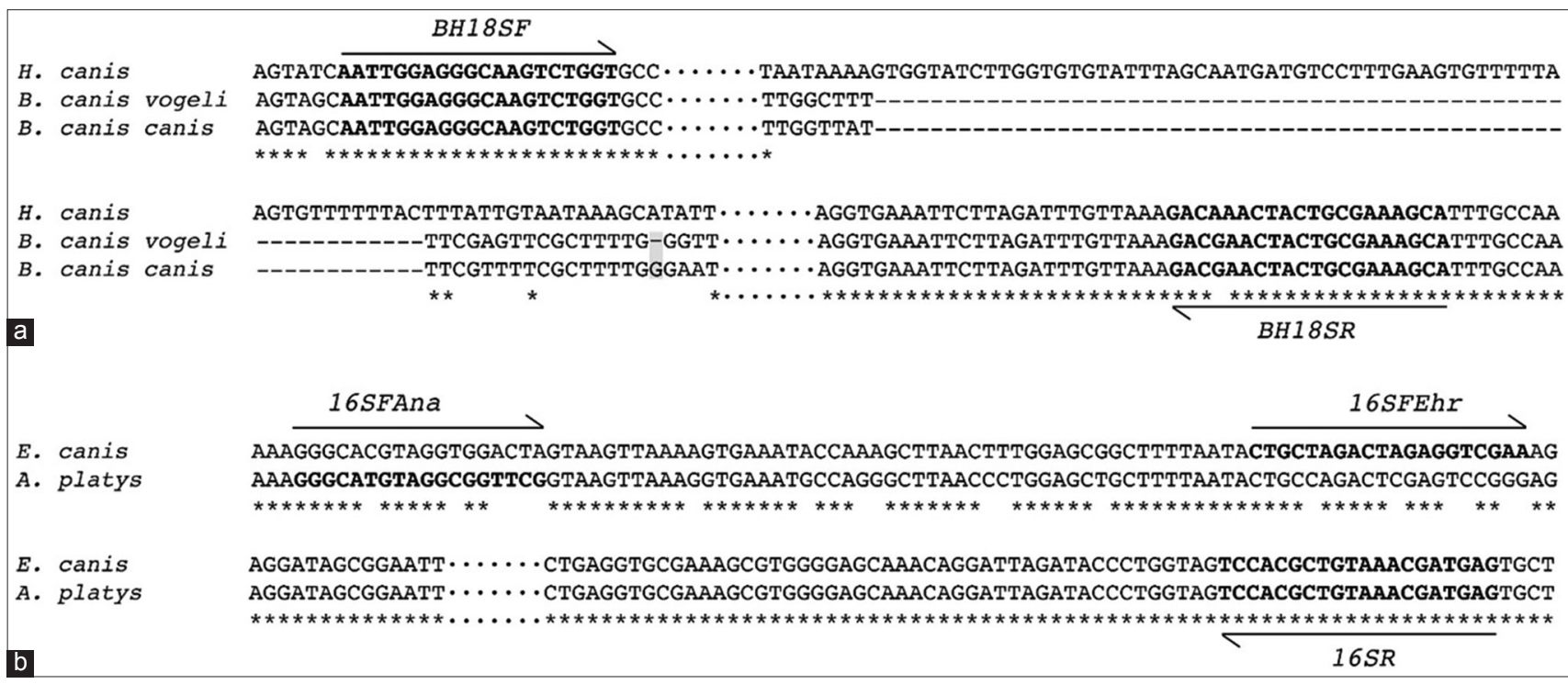

Figure-1: Simplified DNA alignment showing polymorphic regions targeted in primer design of (a) $18 \mathrm{~S}$ rDNA and (b) $16 \mathrm{~S}$ rDNA. Dot symbols show omitted regions that may not be involved in the result interpretation and discussion. Shaded area shows the 1-bp insertion between Babesia canis subspecies. 
bp for H. canis, 181 bp for E. canis, and $250 \mathrm{bp}$ for A. platys. In addition, it should be noted that multiple infections were found in $16.33 \%(8 / 49)$ of dogs. Seven dogs were coinfected with $E$. canis and A. platys and one dog was coinfected with $E$. canis and $H$. canis. The results of the prevalence of each parasite are shown in Table-2. Finally, there were $2.04 \%, 2.04 \%$, $36.73 \%$, and $30.61 \%$ false-negative results detected through microscopic examination of B. canis, $H$. canis, E. canis, and A. platys, respectively.

\section{Discussion}

Although microscopic examination of Giemsastained blood smear is practical and routinely used to detect dog blood parasites infection, the tests do have recognized limitations and require high parasitemia $[9,28]$. The current study revealed that false-negative results were as high as $36.73 \%$ detected through microscopy. Dogs with low numbers of blood parasite infection had few infected cells which hampered the microscopic examination [29]. No dogs in this study have any significant signs of infection. Thus, molecular detection produced better results.

Our results supported the hypothesis that dog blood parasites remain a health problem in dogs in Thailand. We demonstrated that dogs were positive with all four types of blood parasites using the
PCR technique. The prevalence of $B$. canis infection $(2.01 \%)$ was lower than reported in previous studies $(6.3 \%$ and $19.5 \%)$ in the same region of Northeastern Thailand $[3,9]$. Furthermore, a lower prevalence was found in $H$. canis infections $(4.08 \%)$ compared with $10.1 \%, 18.8 \%$, and $11.4 \%$ in previous studies $[3,8,11]$. Interestingly, the molecular prevalence of E. canis infection in dogs with owners in this study $(36.73 \%)$ was higher than the prevalence obtained from stray dogs from Maha Sarakham Province (21.5\%) [3] and domestic dogs from Khon Kaen Province (3\%) [9]. Moreover, the prevalence of $A$. platys (30.61\%) in the present study was higher than that in a previous study in Songkhla Province (4.4\%), Southern Thailand [8]. Most coinfection was found with $E$. canis and A. platys, which may lead to more severe anemia than from a single infection [21]. H. canis and E. canis coinfection was found that agreed with the findings presented in a previous report in Khon Kaen Province [9].

Although PCR has higher sensitivity and specificity than blood smear, the cost and time may remain a major limitation for the use of PCR to detect all common blood parasites. We try to improve the cost-effectiveness of PCR by designing new primers. We successfully detected $B$. canis and $H$. canis using the developed single primer pair providing easy PCR reaction for $B$. canis and $H$. canis

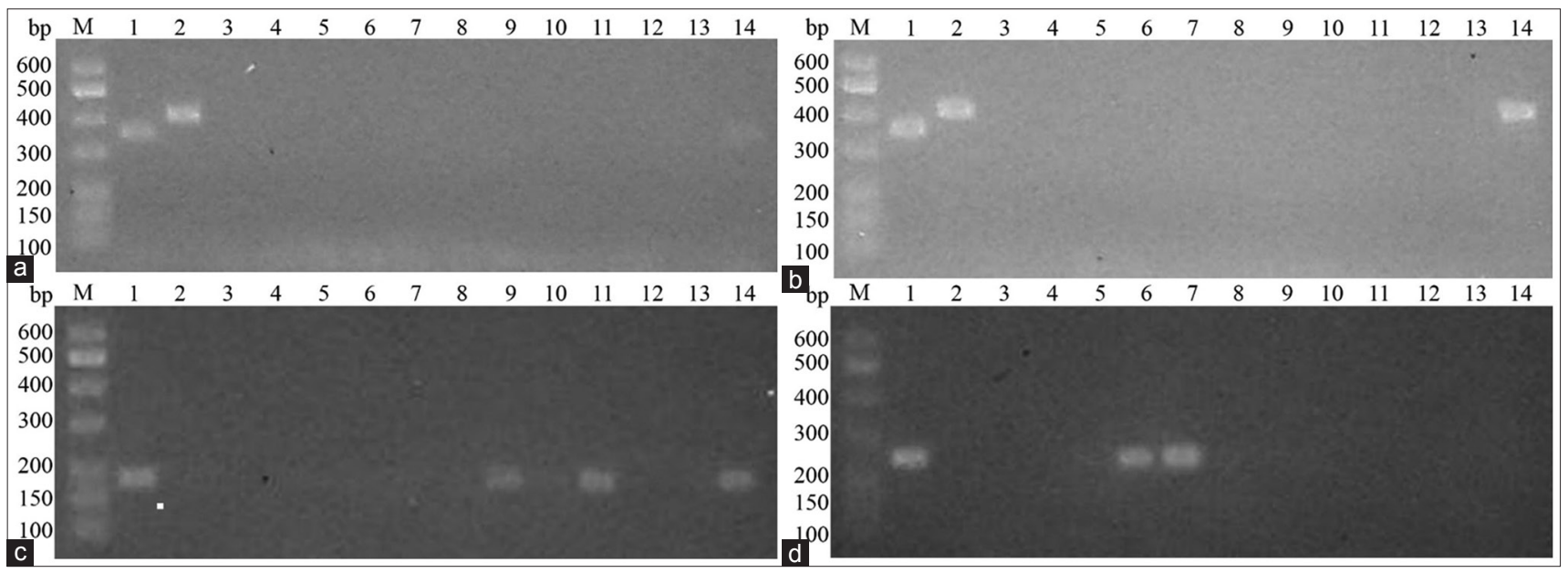

Figure-2: Example of polymerase chain reaction gels of (a) Babesia canis amplicons at 356 bp (b) Hepatozoon canis amplicons at $409 \mathrm{bp}$ ( $a$ and $\mathrm{b}$, Lane $1=B$. canis positive control, Lane $2=\mathrm{H}$. canis positive control, Lanes 3-14 = samples). (c) Example of Ehrlichia canis amplicons at $181 \mathrm{bp}$ and (d) Anaplasma platys amplicons at 250 bp (c and d, Lane $1=$ positive control, Lanes 2-14 = samples). Corresponding lane numbers between figures (a-d) are not related to the same sample.

Table-2: Comparison between blood smear and PCR techniques regarding the prevalence of tick-borne pathogens infection among dogs.

\begin{tabular}{|c|c|c|c|c|}
\hline \multirow{2}{*}{$\begin{array}{l}\text { Pathogen/ } \\
\text { techniques }\end{array}$} & \multicolumn{2}{|c|}{ Blood smear } & \multicolumn{2}{|c|}{ PCR } \\
\hline & $\%$ Positive (number) & $\%$ Negative (number) & $\%$ Positive (number) & $\%$ Negative (number) \\
\hline B. canis vogeli & $0(0)$ & $100(49)$ & $2.04(1)$ & $97.96(48)$ \\
\hline H. canis & $2.04(1)$ & $97.96(48)$ & $4.08(2)$ & $95.92(47)$ \\
\hline E. canis & $0(0)$ & $100(49)$ & $36.73(18)$ & $63.27(31)$ \\
\hline A. platys & $0(0)$ & $100(49)$ & $30.61(15)$ & 69.39 (34) \\
\hline
\end{tabular}

B. canis vogeli=Babesia canis vogeli, $H$. canis=Hepatozoon canis, E. canis=Ehrlichia canis, A. platys=Anaplasma platys, $\mathrm{PCR}=$ Polymerase chain reaction 
in a single tube. This strategy could be applied to the detection of $E$. canis and A. platys since a reaction required the unique forward primer to specifically bind at the 3 ' end of the priming site leading to assessment in one reaction tube. Moreover, all primers used in this study were optimized for the same annealing temperature of $55^{\circ} \mathrm{C}$ allowing all PCR reactions to be simultaneously performed in the same run on the machine. This study used 40 cycles of PCR amplification for the detection of four common blood parasites compared to 35 cycles in other studies $[3,5,6]$ because a faint band was observed when 35 cycles used.

Based on our results, there is a very serious quality problem with blood smear detection. Therefore, we recommend that the diagnosis of blood parasites in dogs should not be based on the routine blood smear technique alone. PCR is endorsed for routine blood parasites diagnosis and also suggested for the screening of blood donors in animal blood banks to prevent blood-borne pathogen transmission $[14,30]$. However, PCR is not suitable for monitoring the response to treatment because the result may be falsely positive for several days after parasites eliminated [31]. This study also suggested that there is an underestimation of the blood parasite prevalence in dogs in Thailand. Our results may provide valuable data for eradication, prevention, and control of dog blood parasites in Buriram Province and other parts of Thailand, which may be at risk of blood parasites infection.

\section{Conclusion}

This study was the first to provide information on the molecular prevalence of four common dog blood parasites: B. canis, H. canis, E. canis, and A. platys using conventional PCR in domestic dogs in Buriram Province, Northeastern Thailand. The results suggested that PCR is an effective method for definitive diagnosis of dog blood parasites infection, particularly in animal hospitals, blood banks and for an epidemiological study.

\section{Authors' Contributions}

RR designed and performed the experiments. $\mathrm{CM}$ and TM performed the experiment. RR, CM, and MS analyzed the data. PK collected the samples. RR and $\mathrm{CM}$ drafted the manuscript. All authors read and approved the final manuscript.

\section{Acknowledgments}

The authors are much grateful to Miss Sakulchit Wichianchot for technical support. This study received financial support from the Kasetsart University Research and Development Institute, Thailand (Grant no. 35.60).

\section{Competing Interests}

The authors declare that they have no competing interests.

\section{Publisher's Note}

Veterinary World remains neutral with regard to jurisdictional claims in published institutional affiliation.

\section{References}

1. Procajlo, A., Skupien, E.M., Bladowski, M. and Lew, S. (2011) Monocytic ehrlichiosis in dogs. Pol. J. Vet. Sci., 14(3): 515-520.

2. Schoeman, J.P. (2009) Canine babesiosis. Onderstepoort J. Vet. Res., 76(1): 59-66.

3. Piratae, S., Pimpjong, K., Vaisusuk, K. and Chatan, W. (2015) Molecular detection of Ehrlichia canis, Hepatozoon canis and Babesia canis vogeli in stray dogs in Mahasarakham province, Thailand. Ann. Parasitol., 61(3): 183-187.

4. Matijatko, V., Kis, I., Torti, M., Brkljacic, M., Kucer, N., Rafaj, R.B., Grden, D., Zivicnjak, T. and Mrljak, V. (2009) Septic shock in canine babesiosis. Vet. Parasitol., 162(3): 263-270.

5. Azhahianambi, P., Jyothimol, G., Baranidharan, G., Aravind, M., Narendran, R.R., Latha, B.R. and Raman, M. (2018) Evaluation of multiplex PCR assay for detection of Babesia spp., Ehrlichia canis and Trypanosoma evansi in dogs. Acta Trop., 188: 58-67.

6. Ahmad, A.S., Saeed, M.A., Rashid, I., Ashraf, K., Shehzad, W., Traub, R.J., Baneth, G. and Jabbar, A. (2018) Molecular characterization of Hepatozoon canis from farm dogs in Pakistan. Parasitol. Res., 117(4): 1131-1138.

7. Andersson, M.O., Tolf, C., Tamba, P., Stefanache, M., Waldenstrom, J., Dobler, G. and Chitimia-Dobler, L. (2017) Canine tick-borne diseases in pet dogs from Romania. Parasit. Vectors, 10(1): 155.

8. Liu, M., Ruttayaporn, N., Saechan, V., Jirapattharasate, C., Vudriko,P.,Moumouni,P.F.,Cao,S.,Inpankaew,T.,Ybanez,A.P., Suzuki, H. and Xuan, X. (2016) Molecular survey of canine vector-borne diseases in stray dogs in Thailand. Parasitol. Int., 65(4): 357-361.

9. Laummaunwai, P., Sriraj, P., Aukkanimart, R., Boonmars, T., Boonjaraspinyo, S., Sangmaneedet, S., Potchimplee, P., Khianman, P. and Maleewong, W. (2014) Molecular detection and treatment of tick-borne pathogens in domestic dogs in Khon Kaen, Northeastern Thailand. Southeast Asian J. Trop. Med. Public Health, 45(5): 1157-1166.

10. Kaewkong, W., Intapan, P.M., Sanpool, O., Janwan, P., Thanchomnang, T., Kongklieng, A., Tantrawatpan, C., Boonmars, T., Lulitanond, V., Taweethavonsawat, P., Chungpivat, S. and Maleewong, W. (2014) High throughput pyrosequencing technology for molecular differential detection of Babesia vogeli, Hepatozoon canis, Ehrlichia canis and Anaplasma platys in canine blood samples. Ticks Tick Borne Dis., 5(4): 381-385.

11. Jittapalapong, S., Rungphisutthipongse, O., Maruyama, S., Schaefer, J.J. and Stich, R.W.(2006)Detection of Hepatozoon canis in stray dogs and cats in Bangkok, Thailand. Ann. N. Y. Acad. Sci., 1081(1): 479-488.

12. Nithikathkul, C., Polseela, R., Iamsa-Ard, J., Wongsawad, C. and Jittapalapong, S. (2005) A study of ectoparasites of Canis lupus familiaris in Mueang district, Khon Kaen, Thailand. Southeast Asian J. Trop. Med. Public Health, 36(4): 149-151.

13. Vascellari, M., Ravagnan, S., Carminato, A., Cazzin, S., Carli, E., Da Rold, G., Lucchese, L., Natale, A., Otranto, D. and Capelli, G. (2016) Exposure to vector-borne pathogens in candidate blood donor and free-roaming dogs of northeast Italy. Parasit. Vectors, 9(1): 369.

14. Stegeman, J.R., Birkenheuer, A.J., Kruger, J.M. and Breitschwerdt, E.B. (2003) Transfusion-associated Babesia gibsoni infection in a dog. J. Am. Vet. Med. Assoc., 222(7): 959-963, 952.

15. Holman, P.J. and Snowden, K.F. (2009) Canine 
hepatozoonosis and babesiosis, and feline cytauxzoonosis. Vet. Clin. North Am. Small Anim. Pract., 39(6): 1035-1053.

16. Harrus, S. and Waner, T. (2011) Diagnosis of canine monocytotropic ehrlichiosis (Ehrlichia canis): An overview. Vet. J., 187(3): 292-296.

17. Bouzouraa, T., Rene-Martellet, M., Chene, J., Attipa, C., Lebert, I., Chalvet-Monfray, K., Cadore, J.L., Halos, L. and Chabanne, L. (2016) Clinical and laboratory features of canine Anaplasma platys infection in 32 naturally infected dogs in the Mediterranean basin. Ticks Tick Borne Dis., 7(6): 1256-1264.

18. Welzl, C., Leisewitz, A.L., Jacobson, L.S., Vaughan-Scott, T. and Myburgh, E. (2001) Systemic inflammatory response syndrome and multiple-organ damage/dysfunction in complicated canine babesiosis. J. S. Afr. Vet. Assoc., 72(3): 158-162.

19. Irwin, P.J. (2010) Canine babesiosis. Vet. Clin. North Am. Small Anim. Pract., 40(6): 1141-1156.

20. Kordick, S.K., Breitschwerdt, E.B., Hegarty, B.C., Southwick, K.L., Colitz, C.M., Hancock, S.I., Bradley, J.M., Rumbough, R., McPherson, J.T. and MacCormack, J.N. (1999) Coinfection with multiple tick-borne pathogens in a Walker Hound kennel in North Carolina. J. Clin. Microbiol., 37(8): 2631-2638.

21. Gaunt, S., Beall, M., Stillman, B., Lorentzen, L., Diniz, P., Chandrashekar, R. and Breitschwerdt, E. (2010) Experimental infection and co-infection of dogs with Anaplasma platys and Ehrlichia canis: Hematologic, serologic and molecular findings. Parasit. Vectors, 3(1): 33.

22. Woody, B.J. and Hoskins, J.D. (1991) Ehrlichial diseases of dogs. Vet. Clin. North Am. Small Anim. Pract., 21(1): 75-98.

23. O'Dwyer, L.H., Massard, C.L. and Pereira de Souza, J.C. (2001) Hepatozoon canis infection associated with dog ticks of rural areas of Rio de Janeiro state, Brazil. Vet. Parasitol., 94(3): 143-150.
24. Yamane, I., Thomford, J.W., Gardner, I.A., Dubey, J.P., Levy, M. and Conrad, P.A. (1993) Evaluation of the indirect fluorescent antibody test for diagnosis of Babesia gibsoni infections in dogs. Am. J. Vet. Res., 54(10): 1579-1584.

25. Waner, T., Strenger, C., Keysary, A. and Harrus, S. (1998) Kinetics of serologic cross-reactions between Ehrlichia canis and the Ehrlichia phagocytophila genogroups in experimental E. canis infection in dogs. Vet. Immunol. Immunopathol., 66(3-4): 237-243.

26. Ano, H., Makimura, S. and Harasawa, R. (2001) Detection of Babesia species from infected dog blood by a polymerase chain reaction. J. Vet. Med. Sci., 63(1): 111-113.

27. Azmi, K., Al-Jawabreh, A., Nasereddin, A., Abdelkader, A., Zaid, T., Ereqat, S., Sawalha, S.S., Baneth, G. and Abdeen, Z. (2017) Detection and molecular identification of Hepatozoon canis and Babesia vogeli from domestic dogs in Palestine. Parasitology, 144(5): 613-621.

28. Aktas, M., Ozubek, S., Altay, K., Ipek, N.D., Balkaya, I., Utuk, A.E., Kirbas, A., Simsek, S. and Dumanli, N. (2015) Molecular detection of tick-borne rickettsial and protozoan pathogens in domestic dogs from Turkey. Parasit. Vectors, 8: 157 .

29. Fukumoto, S., Xuan, X., Shigeno, S., Kimbita, E., Igarashi, I., Nagasawa, H., Fujisaki, K. and Mikami, T. (2001) Development of a polymerase chain reaction method for diagnosing Babesia gibsoni infection in dogs. J. Vet. Med. Sci., 63(9): 977-981.

30. Wardrop, K.J., Birkenheuer, A., Blais, M.C., Callan, M.B., Kohn, B., Lappin, M.R. and Sykes, J. (2016) Update on canine and feline blood donor screening for blood-borne pathogens. J. Vet. Intern. Med., 30(1): 15-35.

31. Rosenblatt, J.E. (2009) Laboratory diagnosis of infections due to blood and tissue parasites. Clin. Infect. Dis., 49(7): 1103-1108. 